\title{
Use of emergency contraceptive pill in India: boon or bane
}

\author{
Anjana Verma ${ }^{1 *}$, Medha Mathur ${ }^{1}$, Jitendra Kumar Meena $^{2}$, \\ Mukesh Kabra ${ }^{1}$, Suresh Choudhary ${ }^{1}$
}

\begin{abstract}
${ }^{1}$ Department of Community Medicine, Geetanjali medical college, Udaipur, Rajasthan, India
${ }^{2}$ Department of Preventive Oncology, Jhajjar, AIIMS, New Delhi
\end{abstract}

Received: 10 November 2020

Accepted: 11 December 2020

\section{*Correspondence:}

Dr. Anjana Verma,

E-mail: anjanaverma504@gmail.com

Copyright: (c) the author(s), publisher and licensee Medip Academy. This is an open-access article distributed under the terms of the Creative Commons Attribution Non-Commercial License, which permits unrestricted non-commercial use, distribution, and reproduction in any medium, provided the original work is properly cited.

\begin{abstract}
It has been almost fifteen years since emergency contraceptive pills (ECPs) have been made available over the counter in India. There have been concerns about the overuse/misuse of ECPs and probability to replace regular contraceptive methods. This article presents various facets of the use of emergency contraceptive pills in India and highlights the importance of potential research to prevent its misuse.
\end{abstract}

Keywords: Emergency contraceptive pill, India, Women, Use, Misuse

\section{INTRODUCTION}

Emergency contraceptive pill (morning-after pill or post coital pill) is recommended to be used within 72 hours after an unprotected sexual intercourse, or after contraceptive accidents like condom rupture or missed pills, in order to prevent pregnancy. Emergency contraceptive pills (ECPs) are meant to be used for emergency only. These are not pertinent for regular use as a contraceptive method since it has higher possibility of failure as compared to other contraceptive methods. In addition, its frequent use can result in side-effects such as menstrual irregularities. In 2005, Indian government took an important decision to make emergency contraceptive pills available over the counter, following which there was a surge in the advertising and marketing campaigns about ECPs. Anecdotal evidence suggests that there has been a rise in the sale of ECPs in the last decade. Most of the healthcare providers appear to have concerns over the overuse/misuse of ECPs and its potential adverse effects on women's health. This article intends to highlight the importance of monitoring the use/ overuse of ECPs in India and the need for future research on the efficacy and side effects of repeat use of the drug.

\section{NEED OF ECP IN INDIA}

Even though a wide variety of contraceptive choices are available in India, contraceptive prevalence in the country is only $53.5 \%$ as per the National family health survey (NFHS) 4 (2015-16). ${ }^{1}$ Most couples in India do not want to use a contraceptive method on a long-term basis for the fear of side-effects, especially the oral pill and IUDs, or do not like to use a method linked with coitus (barrier methods). Hence, unwanted and unplanned pregnancies are common. ${ }^{2}$ As per a study published by S Singh et al the abortion rate in India was 47.0 abortions (42.2-52.1) per 1000 women aged 15-49 years. Abortions accounted for one third of all pregnancies, and nearly half of pregnancies were unintended. ${ }^{3}$ The number of abortions in India is estimated to be over 11 million in a year. Despite abortions being legalized since 1971, there are still 10-11 illegal abortions for each legal abortion. This accounts for about 15,000 to 20,000 abortion-related deaths annually and a high associated morbidity, almost all of which is preventable. ${ }^{4}$ This emphasizes the need to strengthen the use of various contraceptive methods along with an additional 'back-up' method whenever the regular method fails. The demographic surveys have 
revealed a large "unmet need" of contraception in India i.e, $12.9 \%$ as per NFHS $4 .{ }^{1}$ Offering emergency contraception is an important service delivery intervention for reducing this unmet need of contraception. Easy accessibility to ECP has made a huge difference in preventing unwanted pregnancies and deaths due to unsafe abortions. ${ }^{5}$ Birth control is a personal decision for the woman, since it will affect her health and way of life. While the decision to have a baby is every woman's right, population control is a national policy since a huge population increase will affect the resources of the society and hinder development.

\section{USE OF ECP IN INDIA}

According to an audit report by AC Nielsen ORG MARG Research Ltd., which provides some of the most authentic data on pharmaceutical industries, reveals that sale of ECP in last 5 years has increased almost 4 times, from 4.9 million in 2008 to 16.4 million in 2013. The 18 metro cities contribute about 29 percent of the total sales, with highest in Delhi NCR region, followed by Mumbai and Kolkata. However, the accessibility of ECP is low in smaller towns and in the rural areas. Furthermore, the contribution of public health facilities in free distribution of ECP is minimal. The government procures ECPs and provides it free of cost at its health centres as well as at the doorsteps in rural areas through the accredited social health activist (ASHA). ${ }^{6,7}$ However, according to the annual health survey (2010-11), only 0.12 percent of the rural women had ever used ECP. ${ }^{8}$ NFHS 4 shows that $33.6 \%$ percent of women in rural and $47.7 \% \%$ in rural area were aware of ECP. ${ }^{1}$ According to a study done in urban Delhi, 45\% (185) of married women had knowledge about ECP and 9\% (32) had ever used ECP. ${ }^{9,10}$ A study done in Rohtak, Haryana by Dahiya et al in 2012 , revealed that $8.8 \%$ of the women of reproductive age group attending postpartum centre at post graduate Institute of medical sciences (PGIMS) outpatient department had used EC pill. ${ }^{11}$ As per the metanalysis done by Mehta the pooled proportion of women in India, who ever used ECPs was 6\% (95\% confidence interval, $0.03-0.10) .^{12}$

\section{MISUSE OF ECP}

The major concern about over the counter availability of ECP is its overuse/ misuse. Another concern is that its easy availability might replace the regular use of other contraceptive methods. The other perturbations are depriving the client of appropriate counselling and increased risk of reproductive tract infections.

In a prospective cohort study conducted in Karnataka, it was found that most of the women used the method once $(54.1 \%)$; while $24.3 \%$ used it twice; $18.9 \%$ used it thrice, and one woman used it 6 times. ${ }^{13}$ In a study conducted among pharmacists in Delhi, it was reported that only $18 \%$ of the clients were referred by doctors while majority $(82 \%)$ directly approached the pharmacists.
Almost one third of the clients were adolescents. $62 \%$ of the pharmacists claimed that most of the clients repeated the use of ECP during the same month. Two pharmacists claimed that the same clients bought ECPs 30 times in a month. In the same study, it was revealed that only $3.3 \%$ asked about the last menstrual period or the time elapsed since the last unprotected sexual intercourse. Only half of them explained to the client that they may experience side effects. None of the pharmacists advised their clients for a sexually transmitted disease (STD) screening and only $35 \%$ advised about regular contraceptive method. ${ }^{14}$ In a study done by Arora et al among college students in Delhi, it was reported that $28.5 \%$ of study participants used ECP twice in last 1 year and $21.4 \%$ used it three times or more. ${ }^{15}$ In the meta-analysis done by Mehta NR, the proportion of repeat use ranged from $12 \%$ to $69 \% .^{12}$ Khan et al reported that doctors had strong reservations against over the counter availability of ECPs and distribution by pharmacists and community health workers. About $75 \%$ thought that ECP users have multiple sexual partners while almost half of the doctors thought that women using ECPs were more likely to have sexual encounters at a young age. Most of the doctors $(78 \%)$ felt that it should not be used more than once in one menstrual cycle; and not be used as a regular method of contraception. ${ }^{16}$

\section{DISCUSSION}

Reported evidence demonstrates that making ECPs more widely available does not increase risk taking but instead reduces the incidence of unintended pregnancy and that women who are the most diligent about ongoing contraceptive use are those most likely to seek emergency treatment. ${ }^{17,18}$ However, the repeat use of ECPs remains insufficiently explored, because of inconsistent information. There is also a gap in the knowledge about possible adverse health effects of repeat use of ECPs and its contribution in preventing the morbidity and mortality associated with unintended pregnancies. There is a need of conducting longitudinal studies, which can provide information on repeat use in one menstrual cycle, to understand the burden of adverse effects. There is also a need to explore various socio-demographic factors associated with the use and repeat use of ECPs. For unmarried/ single women, accessing ECPs becomes more difficult, because of the judgemental attitude of providers. Moreover, there is a need to destigmatize the conversation about use of contraceptive methods, which can help in providing proper counselling to the clients. Hence sensitization of public and private healthcare providers is crucial.

\section{CONCLUSION}

About $78 \%$ of pregnancies in India are unplanned, and at least $25 \%$ are unwanted. Emergency contraception gives a woman the last opportunity to protect herself from an otherwise unprotected intercourse; it has the potential to achieve the goal of "all pregnancies should be wanted" 
and can be a handy tool to achieve the objectives of national population policy. However, repeat use of ECPs needs to be explored for a better understanding of positive as well as negative health impacts of ECPs, which will be important in shaping the discourse in right direction. The evidence generated can then be used by existing family welfare programmes to refine program strategies.

Funding: No funding sources Conflict of interest: None declared

Ethical approval: Not required

\section{REFERENCES}

1. International Institute of Population Sciences. Family Planning and Contraceptive use. National Family Health Survey (NFHS-4). 2015-16.

2. World Health Statistics 2012. Geneva : World Health Organization. Global Health Indicators;2012.

3. Singh S, Shekhar C, Acharya R, Moore AM, Stillman M, Pradhan MR, et al. The incidence of abortion and unintended pregnancy in India, 2015. Lancet Glob Heal. 2018;6(1):e111-20.

4. Chhabra R, Nuna $\mathrm{S}$, Abortion in India : An Overview. New Delhi; Veerandra Publishers 1993. International Institute of Population Sciences. Family Planning and Contraceptive use. National Family Health Survey (NFHS-2). 1998-99;129-44.

5. Mittal S. Emergency contraception-Potential for women's health. Ind J Medic Res. 2014;140(Suppl 1):S45.

6. Dixit A, Khan ME, Bhatnagar I. Mainstreaming of emergency contraception pill in India: challenges and opportunities. Ind J Comm Medic. 2015;40(1):49.

7. Basu S, Green M. An evaluation of the government of India's initiative on contraceptives at the doorstep by Accredited Social Health Activists (ASHAs) New Delhi: FHI360; 2012.

8. Office of the Registrar General and Census Commissioner, India. Ministry of Home Affairs,
Government of India. New Delhi: ORG; 2010-11. Annual Health Survey (2010-11).

9. Verma A, Singh SV, Gupta VK, Garg S, Meena JK. Knowledge and the factors associated with knowledge of emergency contraception among the married women of 18 to 45 years in an urban area of Delhi. As J Pharmaceut Sci. 2014;4(4):1126-34.

10. Verma A, Singh SV, Gupta VK, Garg S. Attitude, Practice and Need Assessment of Emergency Contraception among Women of Reproductive Age Group in Delhi. J Young Pharmac. 2015;7(4):320.

11. Dahiya K, Mann S, Nanda S. Women's Knowledge and Opinions regarding Emergency Contraception. J South As Federat Obstet Gynaecol. 2012;4(3):151-4.

12. Mehta NR, Darak SS, Parchure RS. The use of emergency contraceptive pills in India: A metaanalysis. Ind J Pub Heal. 20201;64(2):178.

13. Rocca CH, Shankar M, Sreevathsa A, Krishnan S. Acceptability and use of emergency contraception among married women in Bangalore, India. Int $\mathbf{J}$ Gynecol Obstet. 2013;121(1):64-8.

14. Mishra A, Saxena P. Over-the-Counter Sale of Emergency Contraception: A Survey of Pharmacists in D elhi. Sexu Medic. 2013;1(1):16-20.

15. Arora P, Bajpai RC, Srivastava R. Emergency contraception: a study to assess knowledge, attitude and practices among female college students in Delhi. Hospital. 2013;12(6.0):2-7.

16. Khan ME, Dixit A, Bhatnagar I, Brady M. Medical barriers to emergency contraception: a crosssectional survey of doctors in North India. Glob Heal Sci Pract. 2014;2(2):210-8.

17. Glasier A, Baird D. The effects of self-administering emergency contraception. N Engl J Med. 1998;339:1-4.

18. Kosunen E, Sihvo S, Hemminki E. Knowledge and use of hormonal emergency contraception in Finland. Contraception. 1997;55:153-7.

Cite this article as: Verma A, Mathur M, Meena JK, Kabra M, Choudhary S. Use of emergency contraceptive pill in India: boon or bane. Int J Reprod Contracept Obstet Gynecol 2021;10:425-7. 